\title{
Toward universal health coverage in the post-COVID-19 era
}

\author{
Stéphane Verguet ${ }^{1}$, Alemayehu Hailua, ${ }^{2,}$, Getachew Teshome Eregata ${ }^{2,3}$, Solomon Tessema Memirie ${ }^{(1)}$, \\ Kjell Arne Johansson ${ }^{3}$ and Ole Frithjof Norheim ${ }^{1,3 凶}$
}

\begin{abstract}
All countries worldwide have signed up to the United Nations Sustainable Development Goals and have committed to the objective of achieving 'universal health coverage, including financial risk protection, access to quality essential health-care services and access to safe, effective, quality and affordable essential medicines and vaccines for all'. During the COVID-19 pandemic and beyond, advancement toward universal health coverage (UHC) will become more difficult for many countries, demonstrating that locally led priority setting is urgently needed to provide health services with appropriate financial protection to all. Because resources are limited and no national constituency can provide an unlimited number of services to their whole population in a sustainable manner, rationing and setting priorities for the selection of interventions to be included in a defined package of services is critical. In this Perspective, we discuss how packages of essential health services can be developed in resource-constrained settings, and detail how experts and the public can decide on principles and criteria, use a comprehensive array of analytical methods and choose which services to be provided free of charge. We illustrate these main steps while drawing on a recently conducted exercise of revising the national essential health services package in Ethiopia, which we compare with examples from other countries that have defined their essential benefits packages. This Perspective also provides recommendations for other low- and middle-income countries on their pathway to UHC.
\end{abstract}

W ith the momentum of the Millennium Development Goals, low- and middle-income countries (LMICs) have achieved remarkable mortality declines over the past three decades ${ }^{1}$. Yet, for many countries, the COVID-19 pandemic may alter this positive trend and hamper the health system's capacity to deliver essential services and expand access to new services ${ }^{2}$. Concurrent with large reductions in the mortality of children under 5 years of age $^{3}$ and in communicable diseases, the global burden of disease has largely shifted toward non-communicable diseases ${ }^{4}$. For example, Ethiopia-a low-income country with the second largest population of Africa $^{1,5}$ - has substantially curbed child mortality since 1990, which has led to substantial increases in life expectancy (from 47 years in 1990 to 66 years in 2017) ${ }^{1}$. With an aging population, the country is now facing a steadily rising burden of cardiovascular diseases, cancers and injuries ${ }^{4}$ and, as such, it is also more vulnerable to COVID-19. Achieving universal health coverage (UHC) ${ }^{6}$ nevertheless remains a major goal for LMICs, and countries need to adequately plan for this.

Many LMICs had experienced large economic growth before COVID-19. For instance, China and India saw their economies grow between 6 and $8 \%$ per year on average over 2000-2020 . In sub-Saharan Africa, Ethiopia's economy has grown between 8 and $15 \%$ per year over the same time period ${ }^{7}$. Such rapid economic developments have been accompanied by fast urbanization ${ }^{7}$ and the rising influence of urban elites who have voiced their demands for well-run public services including health services.

With economic development, national reforms often take place. For example, in Latin America, several health sector reforms, many of which targeted low-income groups, were enacted over the past 30 years, such as Seguro Popular in Mexico and Acceso Universal con Gariantías Explícitas in Chile ${ }^{8}$. Over the 2000s, China implemented a comprehensive health insurance reform including three schemes that raised insurance coverage ${ }^{9}$; Thailand rolled out its universal coverage program ${ }^{10}$; and, recently, the Philippines embarked on defining a list of high-priority services to be publicly financed ${ }^{11}$. Such UHC-type reforms including pre-payment mechanisms and insurance can often result in increases in health service utilization and reductions in out-of-pocket (OOP) costs for health care $^{12,13}$. In Ethiopia, a publicly financed package of essential health services, including exempted (free) services at the point of care and mainly addressing maternal and child health and communicable diseases, was first introduced in $2005^{14,15}$.

UHC-type reforms often come with defining a national essential benefits package (EBP) to be publicly financed and provided to citizens free of charge. This involves a clear description of the health interventions that are considered to be essential and is a core element of the social contract that fundamentally connects citizens to the elected. Based on agreed, pre-defined criteria that can include disease burden, pro-poor prioritization, political feasibility and so on, health services are selected (or not) for inclusion in the resulting national EBP. As a case in point, Ethiopia has ratified the United Nations Sustainable Development Goals, including Sustainable Development Goal target 3.8: to 'achieve universal health coverage, including financial risk protection, access to quality essential health-care services and access to safe, effective, quality and affordable essential medicines and vaccines for all' $^{6}$. The country is committed to UHC through primary care expansion via strengthening its Health Extension Worker program ${ }^{16}$, and recently (in November 2019), its Federal Ministry of Health (FMOH) launched an expanded package of essential health services as part of this commitment ${ }^{17}$.

Advancing UHC-type reforms will vary from country to country, and there are no one-size-fits-all approaches. History, political leadership, local social and ethical principles, idiosyncrasies of national health systems and, importantly, availability of domestic financial resources will all eventually shape how countries fund and deliver health services in their own sequential realization of $\mathrm{UHC}^{18}$. Since financial resources are limited, especially so in LMICs, many countries will need to design their own health reforms via defining

'Department of Global Health and Population, Harvard T. H. Chan School of Public Health, Boston, MA, USA. ${ }^{2}$ Federal Ministry of Health of Ethiopia, Addis Ababa, Ethiopia. ${ }^{3}$ Department of Global Public Health and Primary Care, University of Bergen, Bergen, Norway. ${ }^{4}$ Department of Pediatrics and Child Health, College of Health Sciences, Addis Ababa University, Addis Ababa, Ethiopia. 凶e-mail: Ole.Norheim@uib.no 
Table 1 | Glossary of key terms used in defining national EBPs

\begin{tabular}{lll} 
Term & Acronym & Definition \\
\hline $\begin{array}{l}\text { Essential benefits } \\
\text { package }\end{array}$ & EBP & $\begin{array}{l}\text { Selection of essential health services } \\
\text { and interventions to be publicly } \\
\text { financed }\end{array}$ \\
\hline $\begin{array}{l}\text { Cost-effectiveness } \\
\text { analysis }\end{array}$ & CEA & $\begin{array}{l}\text { Economic evaluation method that } \\
\text { compares the costs and health } \\
\text { benefits of two alternative scenarios } \\
\text { or interventions }\end{array}$ \\
\hline $\begin{array}{l}\text { Extended } \\
\text { cost-effectiveness } \\
\text { analysis }\end{array}$ & ECEA & $\begin{array}{l}\text { Economic evaluation method } \\
\text { that compares the costs and } \\
\text { health benefits, FRP benefits and } \\
\text { distributional consequences of two } \\
\text { alternative scenarios or interventions }\end{array}$ \\
\hline $\begin{array}{l}\text { Financial risk } \\
\text { protection }\end{array}$ & FRP & $\begin{array}{l}\text { Prevention of medical } \\
\text { impoverishment from OOP direct } \\
\text { health-related expenditures }\end{array}$ \\
\hline Fiscal space analysis & FSA & $\begin{array}{l}\text { Economic analysis that estimates } \\
\text { the domestic financial resources } \\
\text { available to publicly fund an EBP }\end{array}$ \\
\hline Out of pocket & OOP & $\begin{array}{l}\text { Qualifies health-related expenditures } \\
\text { that are financed privately by } \\
\text { individuals and households }\end{array}$ \\
\hline
\end{tabular}

(or revising) a realistic EBP that becomes accessible, free of charge, to all citizens ${ }^{19}$. Choosing an explicit set of essential health services to be publicly funded is a major stepping stone toward UHC. Because no national constituency can provide an unlimited number of services to their whole population in a sustainable manner, prioritizing the interventions to be included in an EBP is a necessity. As a result, countries will achieve better health for all, equitably and without financial hardship.

This Perspective describes how EBPs can be developed in LMIC contexts. It discusses how experts and the public can decide on principles and criteria, use an array of analytical methods and choose which services to be included in EBPs. We draw from the recently completed exercise of revising the national essential health services package in Ethiopia and from a few comparable and well-documented illustrative country cases with defined EBPs. This Perspective does not aim to provide a comprehensive review of experiences from LMICs. Rather, we propose an entry point with useful resources, demonstrating that there exist many possible paths toward defining an EBP. We conclude with some recommendations and lessons learned for Ethiopia and other LMICs on the way to UHC-type reforms.

\section{How to define a national EBP}

In this section, we start by exposing some of the key principles underlying the constitution of a national EBP. Second, we introduce analytical methods consistent with these principles for selecting the interventions in the EBP. Third, we describe the procedural steps necessary to ensure a robust and participative deliberation toward EBP finalization. A glossary of key terms is proposed in Table 1.

Key principles and decision criteria. Priorities must be made in all health systems. Explicit objectives and decision criteria can ensure rationality, consistency and legitimacy for these priorities. There is a growing consensus among scholars with regard to the major objectives of health systems: improved total health and distribution of health; fairness in health sector financing, including financial risk protection (FRP) and its distribution; and responsiveness or citizen satisfaction ${ }^{20-22}$. International organizations (such as the World Health Organization (WHO)) and global consortia (such as the International Decision Support Initiative (iDSI) and Disease Control Priorities (DCP) project) have proposed similar considerations $\mathrm{s}^{21,23-26}$. Overall, levels and distributions of population health and FRP are outcomes that policymakers will aim to maximize under budget constraints.

After selection of key outcomes and decision criteria, two practical tasks follow: to choose indicators that can materialize (quantitatively or qualitatively) these criteria for each intervention considered for inclusion in the EBP; and to populate these indicators with appropriate data for each intervention (see Box 1). For example, for distribution of health, several indicators are typically utilized: socioeconomic status (for example, wealth quintile and educational level), geographical location (for example, administrative region and district) and special populations (for example, women and children). For FRP, direct medical costs for health services, including OOP payments for inpatient or outpatient care, are typical markers. Based on these OOP inputs, estimates of cases of catastrophic expenditures (OOP costs surpassing a certain threshold of household expenditures or income) and impoverishing expenditures (OOP costs pushing households under a defined poverty line) can be computed ${ }^{12,27-29}$.

Main analytical methods. Once key principles and decision criteria have been outlined, the next task is to assemble the EBP or solve the EBP optimization problem (that is, to select the interventions that maximize total population health, reductions in health disparities and FRP, given limited domestic financial resources).

The analytical method commonly used for global health priority setting is cost-effectiveness analysis (CEA). It aims to identify the interventions that maximize total health benefits (without consideration of distribution) per budget expenditure in the health sector $^{30,31}$. CEA focuses on comparing the incremental health benefits (for example, deaths averted or disability-adjusted life years (DALYs) averted) with the incremental costs when providing a health intervention to a given population. As a result, the analyst can rank interventions according to their cost per death or DALY averted and the policymaker can choose to fund the interventions that are most cost-effective (for example, smallest cost per DALY averted). CEA evidence is used in health technology assessment to inform priority setting, and several health technology assessment strengthening exercises have been conducted in LMICs (for example, by iDSI in Africa and $\mathrm{Asia}^{32,33}$ ).

Yet, many have argued that CEA is limited, notably by the lack of attention to distributional consequences of health interventions (for example, distribution of health benefits by socioeconomic group) and to special groups (for example, the worse off), and by the absence of consideration to non-health benefits such as the FRP provided by publicly financed interventions $\mathrm{s}^{30,34}$. Therefore, CEA should be extended to include the major health system objectives described above. This is the primary motivation of extended CEA (ECEA), which explicitly incorporates both distributional outcomes (for example, health and financial gains across disaggregated population subgroups such as socioeconomic groups) and FRP, per given budget expenditure ${ }^{28}$. In sum, extensions of CEA to equity and FRP are essential in defining a fair EBP.

Lastly, budget constraints need to be fully incorporated in the selection of interventions for EBP inclusion, to ensure that health sector finances are maintained at credible levels over time. This comes in two ways. First, fiscal space analysis (FSA $)^{35}$ is necessary to project the future financial resources that will be available to the health sector to fund the EBP. These resources will be composed of a mix of domestic sources, donor funds and private financing by households from OOP payments. Given the plateauing of foreign aid allocations in recent years ${ }^{36}$, mobilization of domestic financing will be essential for LMICs and will increase with the growth of economies and enhanced national commitments of investing in 
Box 1 | Major objectives, selected indicators and analytical methods relevant for undertaking UHC reforms

\author{
Major objectives of health systems and UHC reforms \\ To improve: \\ - Population health \\ - Fair distribution of health in the population \\ - FRP and its distribution in the population \\ - Responsiveness/citizen satisfaction
}

\section{Selected indicators}

- Mortality, morbidity and health-adjusted life expectancy

- Indices of health disparities (for example, related to the distribution of mortality and morbidity across socioeconomic groups)

- Prevalence of catastrophic health expenditures and impoverishing health expenditures

- Amount and distribution of insurance premiums and copayments in the population

\section{Selected analytical methods}

- Clinical effectiveness studies and randomized controlled trials

- CEA

- ECEA

- Budget impact analysis

- Benefit incidence analysis

the health sector (for example, increasing the share of gross domestic product allocated to public health expenditures). Expansion of domestic resources will also crowd out household private financing of health and allow the reduction of OOP payments. Second, within these available fiscal envelopes, one should examine the interventions that can be funded while including both the intervention costs and the opportunity costs of not funding these interventions ${ }^{31}$, until the full available budget is exhausted.

Major steps toward a robust deliberative process. Concurrently, a robust and transparent deliberative process should follow a number of specific steps to ensure legitimacy and eventual EBP uptake by citizens $s^{22,24,37}$. First, professional associations, patient organizations and citizens should be involved in choosing the key principles and decision criteria. Second, there needs to be a comprehensive compilation of appropriate input data contextualized to local settings. Besides the published literature, potential sources include, for example, the iDSI network, the DCP project, WHO databases and the Tufts CEA registry ${ }^{25,38-43}$. Therefore, large amounts of evidence need to be triaged, synthesized and hierarchized through consultations with technical experts, national and regional decision-makers, associations of health providers and patients, the civil society and the public at large. Such transparent involvements will enable translation of evidence into practical policymaker choices for the interventions to be selected (or not) for EBP inclusion.

\section{Constitution of a national EBP}

Combining key principles and analytical methods with a robust deliberative process, we begin with pointing to the main components constitutive of the EBP. We then elaborate on what would be a desirable process for defining the EBP, describe the major stakeholders to be involved and introduce some elements of fiscal space availability. Lastly, we briefly emphasize what should be some of the future essential steps underlying EBP implementation, monitoring and evaluation. In all three instances, we draw from the
Ethiopian EBP exercise ${ }^{17,44}$ and compare it with practice from other countries (see Table 2).

Considering the health services to constitute the EBP. Ultimately, an EBP is constituted of a list of services publicly financed by a government. Three service categorizations can be used in selecting the interventions for inclusion: (1) the disease areas and conditions that the intervention addresses; (2) the levels of the health system via which the intervention will be delivered; and (3) the potential intersectoral (beyond the sole health sector) features that the intervention may have.

As a case in point, Ethiopia's EBP combined interventions addressing broad disease areas with different delivery levels of the health system ${ }^{44}$. Several countries, including Chile and Mexico, have chosen similar paths. For example, Mexico defined a diagonal approach that combined vertical programs and horizontal health system strengthening ${ }^{45}$. In contrast, other countries, such as Malawi and Kenya, have mostly focused on EBPs for primary health care, and thereby explicitly linked services to communitylevel delivery platforms (Table 2). Furthermore, intersectoral features can be emphasized for environmental, water and sanitation interventions, interventions that can be delivered via schools, and behavioral interventions that can be disseminated via mass media campaigns (a detailed typology and discussion is provided by the DCP exercise $\left.{ }^{46}\right)$. Several countries, such as Botswana, Kenya and Rwanda, have included intersectoral interventions in their EBP, while others have only included clinical services (see Table 2). This does not mean that those countries that have only included clinical services do not have intersectoral interventions in their national health policies; rather, they are simply not envisioned as part of EBP. As a result, a complete list of potential interventions for inclusion (preventive, curative and clinical, intersectoral and public health interventions) can be assembled depending on the specificities of the local health system (for example, see the case of Ethiopia; Table 3).

Subsequently, each intervention listed can be ranked along key decision criteria in utilizing analytical methods. In Ethiopia, the first criterion that was systematically assessed across all interventions was cost-effectiveness using CEA. For that purpose, global CEA databases and tools ${ }^{38-40}$, as well as recent publications $s^{25,41,47,48}$, were sourced to rank all interventions for EBP consideration according to cost-effectiveness ${ }^{49}$. Following these rankings, and consistent with ECEA objectives and the ECEA dashboard, interventions were further assigned equity (for example, favoring the poor or not) and FRP scores. Experts were consulted to identify equity-relevant population groups and interventions providing high FRP, which were then given extra weight. Consistent with national policies, equity-relevant groups included children under 5 years of age, pregnant women, the poor and populations living in remote areas ${ }^{50}$. This led to the hierarchization of interventions into three classes of priority: high-, medium- and low-priority services (see Table 3). Other criteria (such as burden of disease to avoid poor intervention relevance) were reviewed, and social and political acceptability were discussed qualitatively during deliberations ${ }^{17,44}$. Beyond Ethiopia, countries differed substantially in their choice of decision criteria. Many countries (for example, Iraq, Kenya, Malawi and the Philippines) only put forward burden of disease or cost-effectiveness, while other countries incorporated a broader set of criteria such as equity, FRP, budget impact, feasibility and social acceptability (see Table 2).

Deliberations toward selecting the interventions. The EBP consultation process needs to be fully participative and to include all relevant stakeholders ${ }^{51,52}$. In Ethiopia, for that purpose, a roadmap was developed by the leadership of the FMOH. The consultation process brought on board a large variety of stakeholders from 
Table 2 | Experience of defining EBPs from selected low-, middle- and high-income countries

\begin{tabular}{|c|c|}
\hline Country (year) & Criteria \\
\hline Ethiopia $(2019)^{17}$ & $\begin{array}{l}\text { Disease burden, } \\
\text { cost-effectiveness, equity, } \\
\text { FRP, budget impact } \\
\text { and public and political } \\
\text { acceptability. }\end{array}$ \\
\hline
\end{tabular}

\begin{tabular}{|c|c|}
\hline Ethiopia $(2005)^{15}$ & $\begin{array}{l}\text { Cost-effectiveness, } \\
\text { affordability, equity, } \\
\text { necessity, capacity and } \\
\text { accessibility. }\end{array}$ \\
\hline Liberia $(2011)^{57}$ & $\begin{array}{l}\text { Burden of disease, } \\
\text { availability of interventions } \\
\text { and feasibility. }\end{array}$ \\
\hline
\end{tabular}

Intersectoral policies

Representatives from communities, districts and national and international organizations involved in determining priority services.

\begin{tabular}{|c|c|}
\hline Malawi $(2016)^{58,59}$ & $\begin{array}{l}\text { Cost-effectiveness, equity, } \\
\text { continuum of care and } \\
\text { complementarity of services }\end{array}$ \\
\hline $\begin{array}{l}\text { Rwanda } \\
(2017 / 2019)^{60-62}\end{array}$ & $\begin{array}{l}\text { Potential contribution in } \\
\text { reducing the burden of } \\
\text { disease, high impact, safe } \\
\text { and effective, feasibility and } \\
\text { sustainability. }\end{array}$ \\
\hline
\end{tabular}

Philippines (2018) $\quad$ Burden of disease and cost-effectiveness.

Kenya $(2015)^{63}$

Burden of disease and cost-effectiveness

Eswatini $(2017)^{64}$

Burden of disease, service availability and public participation.

Botswana $(2010)^{65}$

Burden of disease,

Consultative process with stakeholders to consider a wider set of political, ethical and health system considerations. No detailed description of process.

Ministry of Health responsible for defining package with insurance agency. Consultation with the government cabinet. Published in an official Ministry of Health gazette available to the public

Additions to the package made later (that is, changes to the essential medicines list). No process described.

Based on data analysis. No user involvement described.

Not described.

Consultations with Ministry of Health departments, including a workshop with clinical advisors (health personnel and private/ public hospitals) and development partners.

Consultative process involving cost-effectiveness and equity several stakeholders within and (urban/rural and pro-poor).

Chile $(2005 / 2013)^{66} \quad$ Burden of disease, share of the population suffering from the disease, expected cost per beneficiary, supply capacity of the health system and effectiveness of interventions. outside the health sector.

AUGE Consultative Committee in Ministry of Health defined and revised the package. No detailed description of process.

$\begin{array}{ll}\text { Process and user involvement } & \text { Health services } \\ \text { Participation of internal and } & \text { Comprehensive list of } \\ \text { external stakeholders of the } & \text { interventions from all major } \\ \text { health sector. User involvement } & \text { programs: RMNCH, NCD, injury } \\ \text { through associations and public } & \text { and surgical interventions. }\end{array}$
representatives. Limited direct consultation with citizens.

Developed by the Essential Health Service Package Task Force, FMOH departments and Regional Health Bureaus. User involvement not described. and key stakeholders.

Intersectoral interventions included.

Linked to delivery platforms.

Selective and general. Few NCD services included. Not costed.

Intersectoral collaboration Linked to delivery platforms. encouraged.

Mainly focused on primary health care: $\mathrm{RMNCH}$, some NCDs and surgical and multisectoral interventions. Detailed description of interventions not provided.

Mainly focused on primary health care: $\mathrm{RMNCH}$ and some NCDs.

Selective (detailed description of interventions not provided).

Strategies include engaging in intersectoral activities.

Selective (includes services for 48 conditions). A primary care package is described, but not all interventions are clearly linked to delivery platforms.

Mainly focused on RMNCH, some community-based interventions, NCD screening and WASH. A primary care package is described.

Not described.

Not described.

Mainly focused on RMNCH and Not described. primary care.

Most major program areas

included but details within each program area are limited. Linked to delivery platforms.

Priority interventions

guaranteed in the law to prevent and treat 69 priority health problems. Linked to delivery platforms through clinical practice guidelines. Explicitly mentioned.

Not described.

Not described.

Intersectoral health promotion and preventive interventions to address injuries and violence included.

Not


Table 2 | Experience of defining EBPs from selected low-, middle- and high-income countries (Continued)

\begin{tabular}{|c|c|c|c|c|}
\hline Country (year) & Criteria & Process and user involvement & Health services & Intersectoral policies \\
\hline $\begin{array}{l}\text { Mexico (2012/ } \\
2018)^{67,68}\end{array}$ & $\begin{array}{l}\text { Cost-effectiveness, } \\
\text { affordability, FRP and } \\
\text { scientific community } \\
\text { opinion. }\end{array}$ & $\begin{array}{l}\text { A commission (Comisión } \\
\text { Nacional de Protección Social en } \\
\text { Salud) proposed primary- and } \\
\text { secondary-level services to be } \\
\text { included. The General Health } \\
\text { Council (Consejo de Salubridad } \\
\text { General) identified diseases of } \\
\text { catastrophic nature. } \\
\text { A committee assessing social } \\
\text { acceptability gave general advice. }\end{array}$ & $\begin{array}{l}\text { Linked to delivery platforms } \\
\text { through diagonal programs. } \\
\text { First- and second-level care: } \\
275 \text { interventions. } \\
\text { Catastrophic health fund } \\
\text { (high-cost treatment): } 58 \\
\text { interventions. } \\
\text { Insurance for children: } 128 \\
\text { interventions. }\end{array}$ & Not described. \\
\hline Iraq $(2009)^{69}$ & $\begin{array}{l}\text { Cost-effectiveness and } \\
\text { budget impact. }\end{array}$ & $\begin{array}{l}\text { Technical exercise. No detailed } \\
\text { description of process. }\end{array}$ & $\begin{array}{l}\text { Comprehensive package } \\
\text { linked to service provision in } \\
\text { four layers of health facilities, } \\
\text { starting from community health } \\
\text { up to district hospital level. }\end{array}$ & Not described. \\
\hline Bangladesh $(2015)^{70}$ & $\begin{array}{l}\text { Burden of disease, } \\
\text { cost-effectiveness and FRP. }\end{array}$ & No detailed description of process. & $\begin{array}{l}\text { Comprehensive. Links to delivery } \\
\text { platforms discussed but not } \\
\text { clearly specified. }\end{array}$ & Not described. \\
\hline
\end{tabular}

AUGE, Acceso Universal con Gariantías Explícitas; NCD, non-communicable diseases; RMNCH, reproductive, maternal and child health; WASH, water, sanitation and health.

Table 3 | Selected interventions for inclusion in the essential health services package of Ethiopia, corresponding disease or condition area, health system delivery platform and level of priority assigned in the latest EBP revision (2019)

\begin{tabular}{|c|c|c|c|}
\hline Disease area & Intervention & Health system delivery platform & Priority level \\
\hline $\begin{array}{l}\text { Reproductive, maternal, child health and } \\
\text { nutrition }\end{array}$ & Family planning counseling & All levels & High \\
\hline Major communicable diseases & Tuberculosis diagnosis and treatment & Primary, general and tertiary hospitals & High \\
\hline Non-communicable diseases & Tobacco taxes & Intersectoral & High \\
\hline Non-communicable diseases & $\begin{array}{l}\text { Primary prevention for those with an } \\
\text { absolute } 10 \text {-year risk of CVD of }>20 \%\end{array}$ & $\begin{array}{l}\text { Health centers and primary, general } \\
\text { and tertiary hospitals }\end{array}$ & High \\
\hline Non-communicable diseases & Cervical cancer treatment: stage I & Primary, general and tertiary hospitals & High \\
\hline Non-communicable diseases & Breast cancer treatment: stage IV & Tertiary hospitals & Medium \\
\hline Surgical care & Modified radical mastectomy & General and tertiary hospitals & Medium \\
\hline Emergency care & Advanced management of sepsis & Primary, general and tertiary hospitals & High \\
\hline Health education and promotion & Promote use of fortified products & $\begin{array}{l}\text { Health centers and posts, primary } \\
\text { hospitals and intersectoral }\end{array}$ & High \\
\hline
\end{tabular}

CVD, cardiovascular disease.

health professional associations, members of the public, citizens, policymakers and politicians (Fig. 1). Over one and a half years (2018-2019), the EBP process included a core team of analysts who met regularly with a technical working group appointed by the $\mathrm{FMOH}$ and a larger group of stakeholders ${ }^{44}$. Beyond Ethiopia, countries differed with respect to how inclusive the EBP process was. Some countries, such as Bangladesh, Iraq, Kenya and the Philippines, defined EBPs essentially through technical analyses (or they did not describe the process), while other countries involved key stakeholders within and outside the Ministry of Health, and a few countries involved the general public (see Table 2).
As for financing, in Ethiopia, the total cost of the EBP was estimated for different combinations of interventions ${ }^{53}$. Consistent with this intervention costing exercise, an FSA was conducted for the years 2020-2030. The FSA projected the financial resources that would probably be available to the health sector to fund the EBP in future years, under different sets of aspirational assumptions. The EBP implementation plan included realistic coverage targets that were adjusted in response to available economic and human resources. Comparison of the intervention costing exercise with the FSA chiefly highlighted the urgent need for resource mobilization. This would be realized with increased domestic resources 


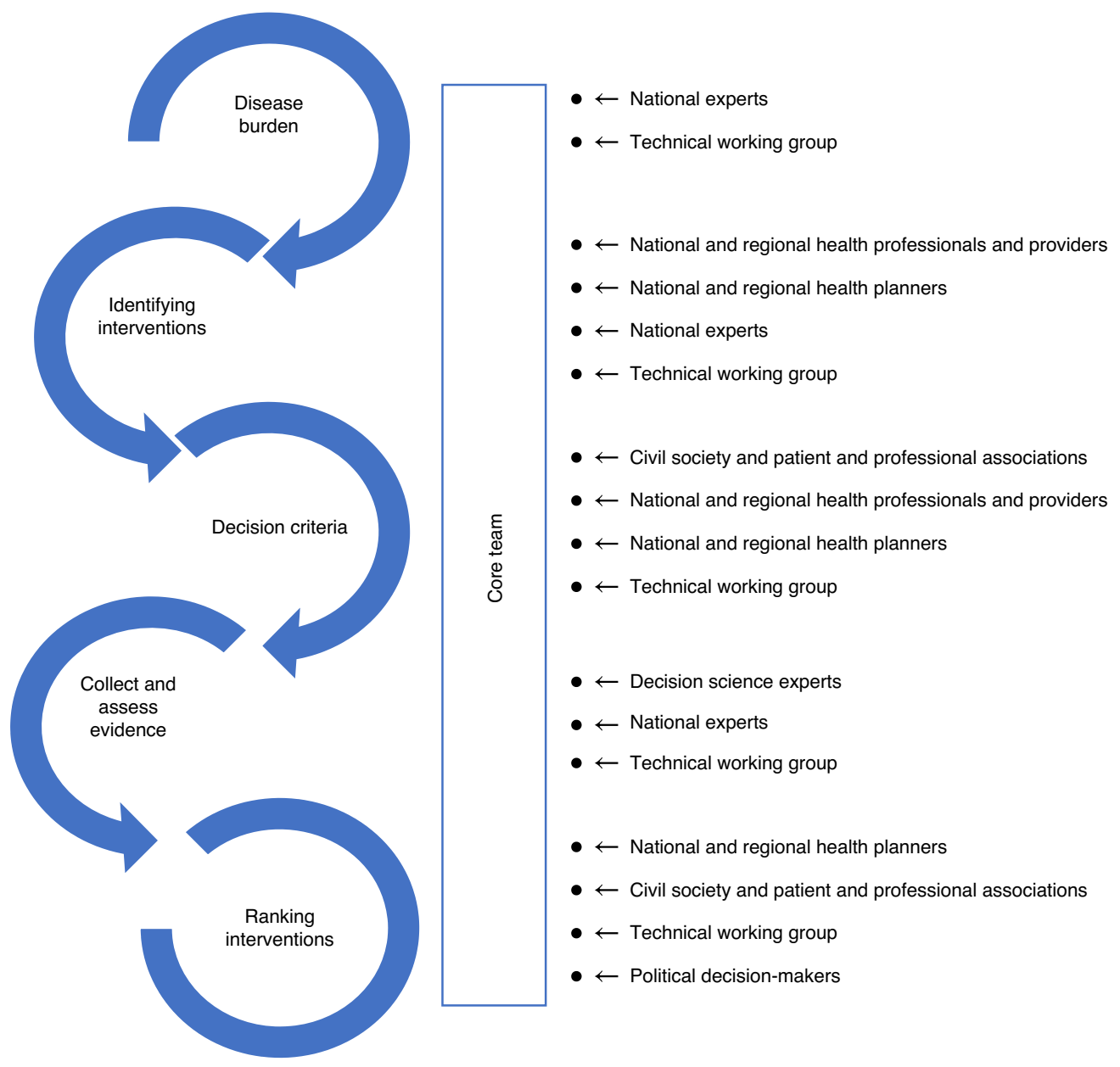

Fig. 1 | Involvement of experts and the public in defining Ethiopia's essential health services package. Ethiopia's essential health services package ${ }^{17}$ was developed through consultation with a core team of stakeholders who determined the burden of disease, identified the required interventions, selected decision criteria, gathered and assessed evidence and ranked the required interventions.

via expanding the political commitment toward the health sector and growing the national taxation base, concurrently with enabling intersectoral measures for raising excise health taxes on harmful products such as tobacco, alcohol and sugary drinks ${ }^{54}$.

Implementation, monitoring and evaluation. Defining the EBP must come hand in hand with delivery to the population via the different levels of the health system and across the health and other sectors (for example, education and transport). The major parts of the EBP will be delivered across all of the regional administrations of a country at the primary health care level, with others delivered in secondary and tertiary hospitals (see the case of Ethiopia ${ }^{17,44}$ ). This will involve consideration of local health system constraints, including human resources requirements (for example, increased numbers of skilled health workers) and facility and infrastructure needs (for example, the need for additional clinics and road construction or upgrading). EBP implementation must be coordinated, locally and nationally, with the appropriate financing mechanisms, including pooling of resources from local users. For example, EBPs could be provided via social health insurance or community-based health insurance as in Ethiopia.

Lastly, a robust monitoring and evaluation framework should be put in place with EBP rollout. This means tracking, before, during and after its introduction, the potential increases and/or decreases in utilization of health services, the possible improvements in health outcomes (for example, reduction in mortality and morbidity) and the possible improvements in FRP, by tracking potential decreases in OOP expenditures and associated catastrophic and impoverishing health expenditures.

\section{Conclusions}

A well-designed EBP will save lives, reduce health disparities and protect against impoverishment ${ }^{55}$. A publicly funded EBP is a major stepping stone toward UHC, and countries can learn from each other on how to best define essential services.

Major lessons learned. The most important driver for the successful development of EBPs is strong political commitment. In Ethiopia, leadership was demonstrated by the $\mathrm{FMOH}$, which included the involvement of a large number of contributors, from the office of the minister to all technical departments and agencies of the FMOH. Such high-level commitment was well observed during workshops and technical consultations that often balanced participation from senior civil servants with input from technical advisers. This strong momentum was also reinforced by the participation of local decision-makers, especially from Ethiopia's Regional Health Bureaus. Similarly, in other countries (for example, Chile, Mexico and Rwanda), strong political leadership was crucial 
(Table 2). Local participation and engagement can foster buy-in and a sense of ownership that will be critical in the EBP implementation phase, via community-based health insurance programs for example. However, one major challenge observed in Ethiopia and many other countries was incomplete information and poor data, along with a lack of available human resources adequately prepared for the conduct of the technical analyses.

Another lesson learned is that countries can vary in the choice of criteria for service inclusion in their EBP (Table 2). This variation in the relative weight of priority criteria may be explained by local values and policy objectives, access to data and evidence, but also by occasional competing technical advice from national and international experts. Historically, there has been little consensus on the appropriate set of criteria, while more recently we have observed a convergence around criteria directly underpinning the definition of UHC (for example, cost-effectiveness, equity and FRP).

Finally, a comment on COVID-19 and UHC. In responding to the pandemic, Ethiopia decided early on to maintain essential health services as a key component of its COVID-19 response: the FMOH prepared the Implementation Guide for Non-COVID-19 Essential Health Services in Ethiopia During COVID-19 Pandemic in April $2020^{56}$, using the discussed $\mathrm{EBP}^{17}$ as a guide for the protection of priority interventions during the pandemic.

Recommendations for defining EBPs in LMICs. First, one major outcome from the Ethiopian exercise was the substantial subject matter expertise developed (that is, the use of key principles and decision criteria; analytical methods; and implementation of a deliberative process). Such procedures could be replicated to other future priority-setting exercises and to other countries while adapting to the specificities of the local contexts. Second, strong political commitment at the highest levels of the government, and relayed via technical experts and local decision-makers, was essential: defining an EBP will require involving a large number of disparate stakeholders and ensuring that their voices are heard while sustaining support from senior officials. Finally, EBP contextualization is critical. While global data from international databases (for example, the WHO) are useful inputs, and examples of already established EBPs in other countries (for example, Ghana, the Philippines, Rwanda and Thailand) are aspirational, adapting such knowledge to local realities and constraints is essential to ensure relevance of the EBP, a sense of local ownership and, eventually, EBP uptake.

Received: 17 October 2020; Accepted: 27 January 2021; Published online: 15 March 2021

\section{References}

1. World Population Prospects 2019 (Department of Economic and Social Affairs, United Nations, 2019).

2. Blanchet, K. et al. Protecting essential health services in low-income and middle-income countries and humanitarian settings while responding to the COVID-19 pandemic. BMJ Glob. Health 5, e003675 (2020).

3. Stillbirth and Child Mortality Estimates (Inter-Agency Group for Child and Mortality Estimation, United Nations, 2020); https://childmortality.org

4. Global Burden of Disease Study 2017 (Institute for Health Metrics and Evaluation, Univ. Washington, 2019); http://ghdx.healthdata.org/gbd-2017

5. World Bank Country and Lending Groups (World Bank, 2020); https:// datahelpdesk.worldbank.org/knowledgebase/articles/906519-world-bank-co untryand-lending-groups

6. Transforming our World: the 2030 Agenda for Sustainable Development Resolution adopted by the General Assembly on 25 September 2015. A/RES/ 70/1 (United National General Assembly, 2015).

7. World Development Indicators (World Bank, 2020); https://databank worldbank.org/reports.aspx?source=world-development-indicators

8. Atun, R. et al. Health-system reform and universal health coverage in Latin America. Lancet 385, 1230-1247 (2015).

9. Yip, W. C. et al. Early appraisal of China's huge and complex health-care reforms. Lancet 379, 833-842 (2012).

10. Reich, M. R. et al. Moving towards universal health coverage: lessons from 11 country studies. Lancet 387, 811-816 (2016).
11. Wong, J. Q. U. et al. Priority setting for health service coverage decisions supported by public spending: experience from the Philippines. Health Syst. Reform 4, 19-29 (2018).

12. Wagstaff, A. et al. Progress on catastrophic health spending in 133 countries: a retrospective observational study. Lancet Glob. Health $\mathbf{6}$, e169-e179 (2018).

13. Erlangga, D., Suhrcke, M., Ali, S. \& Bloor, K. The impact of public health insurance on health care utilisation, financial protection and health status in low- and middle-income countries: a systematic review. PLOS ONE 14, e0219731 (2019)

14. Woldemariam, A. T. H. et al. Redefining Ethiopia's Essential Healthcare Package on the Path Towards Universal Health Coverage: The What and How. DCP3 (Disease Control Priorities, Third Edition), Working Paper No. 18. (Univ. Washington, 2017).

15. Essential Health Service Package for Ethiopia (Federal Ministry of Health of Ethiopia, 2005).

16. Assefa, Y., Gelaw, Y. A., Hill, P. S., Taye, B. W. \& Van Damme, W. Community health extension program of Ethiopia, 2003-2018: successes and challenges toward universal coverage for primary healthcare services. Glob. Health $\mathbf{1 5}$ 24 (2019)

17. Ethiopia's Essential Health Services Package (Federal Ministry of Health of Ethiopia, 2019).

18. Cotlear, D., Nagpal, S., Smith, O., Tandon, A. \& Cortez, R. Going Universal: How 24 Developing Countries Are Implementing Universal Health Coverage Reforms from the Bottom Up (World Bank, 2015).

19. Rumbold, B. et al. Universal health coverage, priority setting, and the human right to health. Lancet 390, 712-714 (2017).

20. Roberts, M. J. H., Berman, W. C. \& Reich, P. M. R. Getting Health Reform Right: a Guide to Improving Performance and Equity (Oxford Univ. Press, 2019).

21. Murray, C. J. \& Frenk, J. A framework for assessing the performance of health systems. Bull. World Health Organ. 78, 717-731 (2000).

22. Norheim, O. F. Ethical priority setting for universal health coverage: challenges in deciding upon fair distribution of health services. BMC Med. 14, 75 (2016).

23. World Health Report. Health Systems Financing: The Path to Universal Coverage (World Health Organization, 2010).

24. Making Fair Choices on the Path to Universal Health Coverage Final report of the WHO Consultative Group on Equity and Universal Health Coverage (WHO, 2014).

25. Jamison, D. T. et al. Universal health coverage and intersectoral action for health: key messages from Disease Control Priorities, 3rd edition. Lancet 391, 1108-1120 (2018).

26. Glassman, A., Giedion, U. \& Smith, P. C. What's In, What's Out? Designing Benefits for Universal Health Coverage (Center for Global Development, 2017).

27. Tracking Universal Health Coverage: 2017 Global Monitoring Report (World Health Organization \& World Bank, 2017)

28. Verguet, S., Kim, J. J. \& Jamison, D. T. Extended cost-effectiveness analysis for health policy assessment: a tutorial. Pharmacoeconomics 34, 913-923 (2016).

29. Hakenstad, A., Coates, M., Marx, A., Bukhman, G. \& Verguet, S. Disaggregating catastrophic health expenditure by disease area: cross-country estimates based on the World Health Surveys. BMC Med. 17, 36 (2019).

30. Neumann, P. J., Ganiats, T.G., Russell, L. B., Sanders, G. D. \& Siegel, J. Cost-Effectiveness in Health and Medicine 2nd edn (Oxford Univ. Press, 2016).

31. Drummond, M. F., Sculpher, M., Claxton, K., Stoddart, G. L. \& Torrance, G. W. Methods for the Economic Evaluation of Health Care Programmes (Oxford Univ. Press, 2015).

32. Hollingworth, S. A., Ruiz, F., Gad, M. \& Chalkidou, K.Health technology assessment capacity at national level in sub-Saharan Africa: an initial survey of stakeholders [version 1; peer review: 2 approved]. F1000Research 9 , 364 (2020).

33. Dabak, S. V. et al. Budgeting for a billion: applying health technology assessment (HTA) for universal health coverage in India. Health Res. Policy Syst. 16, 115 (2018).

34. Cookson, R. et al. Using cost-effectiveness analysis to address health equity concerns. Value Health 20, 206-212 (2017)

35. McIntyre, D. \& Meheus, F. Fiscal Space for Domestic Funding of Health and Other Social Services Working Group on Financing Paper 5 (Chatham House, 2014)

36. Financing Global Health (Institute for Health Metrics and Evaluation, Univ. Washington, 2020); http://vizhub.healthdata.org/fgh/

37. Baltussen, R. et al. Multicriteria decision analysis to support health technology assessment agencies: benefits, limitations, and the way forward. Value Health 22, 1283-1288 (2019).

38. DCP3 (Disease Control Priorities, Third Edition). (Univ. Washington, 2018); http://dcp-3.org

39. Cost-Effectiveness and Strategic Planning (WHO-CHOICE) (World Health Organization, 2020); https://www.who.int/choice/results/en/

40. Cost-Effectiveness Analysis (CEA) Registry (Center for Evaluation of Value and Risk in Health, 2020); https://cevr.tuftsmedicalcenter.org/databases/cea-registry 
41. Stenberg, K. et al. Financing transformative health systems towards achievement of the health Sustainable Development Goals: a model for projected resource needs in 67 low-income and middle-income countries. Lancet Glob. Health 5, e875-e887 (2017).

42. Wilkinson, T. et al. The international decision support initiative reference case for economic evaluation: an aid to thought. Value Health 19, 921-928 (2016).

43. International Decision Support Initiative. The reference case for economic evaluation. https://www.idsihealth.org/resource-items/idsi-reference-case-foreconomic-evaluation/ (accessed 22 December 2020).

44. Eregata, G. T. et al. Revision of the Ethiopian essential health service package: an explication of the process and methods used. Health Syst. Reform 6, e1829313 (2020)

45. Sepúlveda, J. et al. Improvement of child survival in Mexico: the diagonal approach. Lancet 368, 2017-2027 (2006).

46. Watkins, D. A. et al. in Disease Control Priorities: Improving Health and Reducing Poverty 3rd edn (eds Jamison, D. T. et al.) Ch. 2 (World Bank, 2017).

47. Johansson, K. A. et al. Country contextualisation of cost-effectiveness studies: lessons from Ethiopia. BMJ Glob. Health 4, e001320 (2019).

48. Verguet, S. et al. Health gains and financial risk protection afforded by public financing of selected interventions in Ethiopia: an extended cost-effectiveness analysis. Lancet Glob. Health 3, e288-e296 (2015).

49. Eregata, G. T. et al. Generalised cost-effectiveness analysis of 159 health interventions for the Ethiopian essential health service package. Cost. Eff. Resour. Alloc. 19, 2 (2021).

50. Health Sector Transformation Plan 1015/16-2019/20 (2008-2012 EFY) (Federal Ministry of Health of Ethiopia, 2015).

51. Daniels, N. \& Sabin, J. E. Setting Limits Fairly: Can We Learn to Share Medical Resources? 2nd edn (Oxford Univ. Press, 2008).

52. McCoy, M., Schmidt, H. \& Prah Ruger, J. D. in Global Health Priority-Setting: Beyond Cost-Effectiveness (eds. Norheim, O. F. et al.) Ch. 16 (Oxford Univ. Press, 2020).

53. Hailu, A., Eregata, G. T., Stenberg, K. \& Norheim, O. F. Is universal health coverage affordable? Estimated costs and fiscal space analysis for the Ethiopian Essential Health Services Package. Health Syst. Reform (in the press).

54. Ethiopia passes landmark excise tax bill on cigarettes. Health Policy Watch https://www.healthpolicy-watch.org/ethiopia-passes-landmark-smokingexcise-bill/ (2020).

55. Glassman, A., Giedion, U. \& Smith, P. C. in What's In, What's Out? Designing Benefits for Universal Health Coverage (ed. Glassman, A. et al.) 141-153 (Center for Global Development, 2017).

56. Implementation Guide for Non-COVID-19 Essential Health Services in Ethiopia During COVID-19 Pandemic (Federal Ministry of Health of Ethiopia, 2020)

57. Liberia Essential Packages of Health Services (Ministry of Health and Social Affairs, 2011).

58. Ochalek, J., Claxton, K., Revill, P., Sculpher, M. \& Rollinger, A. Supporting the Development of an Essential Health Package: Principles and Initial Assessment for Malawi (Centre for Health Economics, Univ. York, 2016).

59. Manthalu, G., Nkhoma, D., Ochalek, J. M., Phillips, A. \& Revill, P. in What's In, What's Out? Designing Benefits for Universal Health Coverage (eds. Glassman, A. et al.) 235-246 (Center for Global Development, 2017).
60. Extended Health Service Packages for Upgraded Health Centers (Republic of Rwanda Ministry of Health, 2019).

61. Health Service Packages for Public Health Facilities (Republic of Rwanda Ministry of Health, 2017).

62. Wright, J. Essential Package of Health Services: Country Snapshot: Rwanda (Abt Associates, 2015).

63. Wright, J. Essential Package of Health Services: Country Snapshot: Kenya (Abt Associates, 2015).

64. Sundewall, J. \& Brady, E. Prioritizing Essential Packages of Health Services in Six Countries in Sub-Saharan Africa (Swedish International Development Cooperation Agency, 2019).

65. The Essential Health Service Package for Botswana (Ministry of Health, Government of Botswana, 2010).

66. Bitran, R. Explicit Health Guarantees for Chileans. The AUGE Benefits Package UNICO Studies Series; No. 21 (World Bank, 2013).

67. Chemor Ruiz, A., Ratsch, A. E. O. \& Alamilla Martínez, G. A. Mexico's Seguro Popular: achievements and challenges. Health Syst. Reform 4, 194-202 (2018)

68. Gonzalez-Pier, E. et al. Priority setting for health interventions in Mexico's System of Social Protection in Health. Lancet 368, $1608-1618$ (2006).

69. A Basic Health Services Package for Iraq (Ministry of Health of Iraq, 2009).

70. Bangladesh Essential Health Service Package (Ministry of Health and Family Welfare, 2016).

\section{Acknowledgements}

The Disease Control Priorities-Ethiopia project of the University of Bergen and Harvard T. H. Chan School of Public Health, which supported the revision of Ethiopia's essential health services package, is funded by the Bill \& Melinda Gates Foundation (INV-010174). We thank the World Health Organization for technical support throughout the process.

\section{Competing interests}

G.T.E. and A.H. were employees at the Federal Ministry of Health of Ethiopia during the process of revising Ethiopia's essential health services package. The other authors declare no competing interests.

\section{Additional information}

Correspondence should be addressed to O.F.N.

Peer review information Joao Monteiro was the primary editor on this article and managed its editorial process and peer review in collaboration with the rest of the editorial team.

Reprints and permissions information is available at www.nature.com/reprints.

Publisher's note Springer Nature remains neutral with regard to jurisdictional claims in published maps and institutional affiliations.

(C) Springer Nature America, Inc. 2021 